\title{
Learning Characteristics of Field-Dependent Children Within an Analytical Concept-Based Curriculum
}

\author{
Catherine D. Ennis \\ University of Maryland
}

\author{
Jepkorir R. Chepyator-Thomson \\ State University of New York-Brockport
}

\begin{abstract}
The purpose of this research was the examination of the field-dependent/ independent cognitive style as it related to learning within a Logsdon-based movement curriculum. Subjects consisted of 104 children scoring in the 1st- (field independent) and 4th-quartile (field dependent) on the Children's Embedded Figures Test. Observation and interview data were collected by the two researchers over a 4-month period. Data were analyzed using constant comparison. Field-independent students' performance was consistent with teacher expectations during the majority of the classes observed. Fielddependent students experienced difficulty focusing on lesson discussion, following directions, and working independently. The discussion focused on the role of structure and the influence of social relationships on learning behaviors of field-dependent children.
\end{abstract}

Saracho (1989) argued that incompatibility of cognitive style may be responsible for many of the learning problems of young children. More (1987) defines cognitive styles as "pervasive psychological characteristics which cut across intellectual, perceptual, and interpersonal functioning"' (p. 18). A theoretical explanation for student preferences for content structure is provided by the cognitive style described as field dependence/independence (Witkin, Moore, Goodenough, \& Cox, 1977). Field dependence/independence, according to More, is the degree to which an individual can distinguish "a figure from its background, a part from the whole, or oneself from the environment and other people" (p. 21). Although this may appear to be an abstract psychological distinction, it can be quite influential in designing learning environments that are meaningful and relevant to each child. The disparity that arises when one is required to learn using a nonpreferred style has been described by Cohen (1969) as culture conflict.

Culture conflict is of particular concern in subjects where students are encouraged to analyze concepts cognitively and select salient information from

Catherine D. Ennis is with the Department of Kinesiology at the University of Maryland, College Park, MD 20742-2611. Jepkorir R. Chepyator-Thomson is with the Department of Physical Education and Sport at the State University of New YorkBrockport, NY 14420. 
an array of interesting alternatives. As concept-based curricula continue to gain attention in education (Resnick \& Klopfer, 1989), teachers and researchers must avoid inadvertently excluding children based on cognitive style. Curricular models in elementary physical education have also been influenced by an emphasis on cognitive or analytical curricular approaches. Here the focus on the understanding of movement concepts is integrated with the traditional goals of movement performance. Curricular approaches with this emphasis (e.g., Graham, Holt/Hale, \& Parker, 1987; Logsdon et al., 1984; Nichols, 1990) have increased the importance of cognitive goals in physical education programs for young children. An examination of the learning behaviors associated with cognitive style can assist physical educators and curriculum specialists to better address each child's unique learning needs.

This research is based on a naturalistic study conducted in elementary physical education programs taught using the Logsdon et al. (1984) curriculum in two racially integrated elementary schools in the midwestern United States. The research examined cognitive style as it related to learning within an analytical concept-based curriculum.

The significance of the research lies in the investigation of the effects of cognitive style on learning in actual physical education class settings. Culture conflict results when children are required to learn in an educational environment that is different and at times contradictory to their preferred cognitive style. This presents educational problems because they do not achieve academically and because they are frequent perpetrators of behaviors that disrupt the learning environment for others. Unfortunately, these children are often handled as discipline problems rather than learning problems. Cognitive styles and the concept of culture conflict provide a less punitive avenue for understanding field-dependent children and for making deliberate curricular changes to address specific manifestations of incompatibility evident in lesson structures and social interactions. The results should have important implications with respect to ways in which curricular materials or teaching methods might be adapted to meet the needs of students with a field-dependent cognitive style.

\section{Cognitive Style}

Characteristics of individuals with field-dependent (FD) and fieldindependent (FI) cognitive styles have been described in numerous research studies (e.g., Bertini, Pizzamiglio, \& Wapner, 1986; Kogan, 1987; Witkin \& Goodenough, 1981; Witkin et al., 1973). At the core of field dependence/independence (FDI) are basic differences in perceptual differentiation and structuring (Witkin, Dyk, Faterson, Goodenough, \& Karp, 1962). Characteristics of FI and FD learners are summarized in Table 1.

Adults and children described as field independent are highly analytical in their approach to a problem (Davis \& Cochran, 1989). They are able to separate a task into its component parts and examine each independently. These individuals are autonomous and appear to work most comfortably in an independent environment. Criteria for successful performance are personally constructed or derived from the environment itself. FI individuals tend to view the world objectively and to make decisions based on an internal synthesis of relevant factors. 
Table 1

Behavioral Profiles of Field-Dependent and Field-Independent Learners ${ }^{a}$

Field Independent

Approach problems analytically

Stimulus centered

Focus is on parts of object

Ability to perceive abstract, obscure features

Ability to impose internally constructed framework to organize information

High ability to detect change in monotonous, but constantly changing perceptual field over a long period of time

Long attention/concentration span (not easily distracted)

Perceives teacher as information source

Prefers nonsocial learning

Criteria for acceptable performance based on an internal analysis and synthesis of available information
Field Dependent

Approach problems in relational/social mode

Person centered

Focus on global characteristics of object

Perception of obvious or clearly stated features

Adept at using relational skills to acquire a structuring framework from others

Low ability to detect changes in monotonous, but constantly changing perceptual field

Short attention/concentration span (easily distracted)

Perceives teacher as individual

Prefers social learning environment

Criteria for acceptable performance based on a consensus of social group, observations of others, or other social interactions

${ }^{a}$ Characteristics derived from Cohen (1969), Hale-Benson (1986), and Witkin (1978).

They work most effectively in situations where independent analysis requiring extended periods of concentration is necessary for completion of a project or solution of a problem (Kogan \& Saarni, 1989). They tend to have a sense of separate identity with internalized values and standards that permits them to function with a degree of independence of social field (Goodenough, 1976). On the other hand, they may be criticized for their inability to work cooperatively with others or to relate to others in situations where group discussion is critical to achievement.

Conversely, individuals characterized as field dependent are especially effective in situations where collaboration and social relationships contribute to success (Witkin et al., 1962). Cohen (1968) described these individuals as highly relational because they are positively influenced by group goals and derive evaluative criteria from social interaction. FD individuals view the task as a whole without attempting to discern distinctions. In perceptual and problem-solving tasks, they assume that the organization of a given background knowledge is correct and do not question the stated structure (Goodenough, 1976). These individuals are less likely to be successful in situations where they are required to analyze problems independently, concentrate on a problem for an extended period of time, or generate an organizing framework to articulate a concept or solution.

Cohen (1968) argued that highly analytical or field-independent environments are frequently the only learning options offered in schools. She contends 
that all children are required to adapt to this style at an increasingly early age or face the prospect of academic failure. Winnie and Marx (1982) suggest that children's success in acquiring intended classroom knowledge largely depends on their ability to perceive information correctly-the way the teacher intended them to process it. Indeed, according to Marx, Howard, and Winnie (1987), "the student's perceptions of instructional cues and intended cognitive responses can serve as mediating links between the teacher's behavior and the student's learning of curriculum presented by instruction" (p. 132). If these perceptions are inaccurate, then the child is viewed as either disruptive, nonconforming, or unintelligent. Learning problems are compounded for FD children when they are required to work alone on abstract problems that are difficult to conceptualize. In these situations, criteria for successful performance are based on factual data embedded in teacher explanation or textbook description. FD children progressively find these curricula meaningless and unrelated to the valued aspects of their lives (Cohen, 1968).

In the United States, students with FD cognitive styles represent a variety of cultural and socioeconomic backgrounds (e.g., Banks, 1987; Cohen, 1968; Diessner \& Walker, 1986; Gonzales \& Roll, 1985; Hale-Benson, 1986; Hvitfeldt, 1986; Kagan \& Zahn, 1975; More, 1987). In attempts to investigate the origin of this phenomena, researchers (e.g., Cohen, 1968; Cohen, 1969; Kogan \& Saarni, 1989; Oltman, 1986; Witkin, 1978) have identified relevant social variables such as family- and friendship-group structure that have been confirmed to some degree cross-culturally (Oltman, 1986). Specifically, Cohen (1968) found that FD children were more likely to lack an organized, formal family structure, Regardless of the ethnic origins, individuals within these families were not assigned status roles but performed critical functions indiscriminately or in a shared manner. Children assumed responsibilities within this cooperative structure. They were not encouraged to make decisions independently or to play or congregate beyond the confines of the shared family environment.

This highly interdependent, nonautonomous environment is often alien to the impersonal academic settings typically associated with many American schools (Wehlage, Rutter, Smith, Lesko, \& Fernandez, 1989). The nurturing atmosphere thought to be associated with academic achievement, self-concept of academic ability, and sense of academic efficacy (Bookover et al., 1978) are frequently absent, perhaps contributing to many of the difficulties that FD children experience early in their school careers. Cohen (1968) asserts that these phenomena are manifestations of culture conflict- "different and/or conflicting conceptual skills between those required by the school and its test instruments and those brought to the school by pupils from shared function primary group environments"' (p. 208). Although FD children may be superior to FI children in their interpersonal and social skills, they are rarely praised or rewarded for these abilities in schools. Instead they may be viewed as disruptive and lacking in the academic skills valued in educational settings.

\section{Logsdon Curriculum}

The Logsdon et al. (1984) curriculum couched within the Laban movement framework is described as an analytical or field-independent curriculum because of its emphasis on the examination of the movement process and the analysis of 
game, dance, and gymnastics activities (Ennis, 1990; Ennis, in press). Lessons are frequently designed to assist students in breaking down specific components of skill and movement fundamentals (Ennis, in press). Although students are typically involved in movement activities, significant portions of many lessons encourage students to think reflectively about the movement process. Teachers use questioning, problem solving, and decision making to focus a student's attention on the key aspects of a movement and to integrate the student's knowledge into an increasingly more skillful performance (Ennis, 1990). The curricular approach has been both applauded for its movement emphasis and criticized for its "intellectualization" of movement activities (Jewett \& Bain, 1985).

Because learners in physical education taught with a movement approach rarely use workbooks or textbooks, the teacher serves as the principal source of information. Thus, children depend on the teacher for content as well as behavioral cues. In order to be successful, students attend to the teacher's direction, concentrate on the task to be performed, and compare their performance with the evaluative criteria stated by the teacher. Once the brief discussion section of the lesson is completed, children are encouraged to remember the directions and discipline themselves to follow through with the prescribed action (Ennis, in press).

The nature of the content and learning environment appears to be more compatible with the preferred learning behaviors of FI children. The emphasis on analyzing movement, integrating information from movement concepts, and working autonomously seems best suited for these individuals. Conversely, this approach may provide an alien environment for students who perceive the task as a whole and prefer to learn socially. Curricula structured from an analytical perspective may not be as relevant or interesting to FD students.

Therefore, the goal of this research was to examine the extent to which children were able to demonstrate learning behaviors within the environment created by the analytical curriculum. Observations and interviews of teachers and children were used to investigate the educational setting created by two expert physical educators using the Logsdon curriculum.

\section{Method}

\section{Subjects}

Two elementary physical education specialists and the students in four of their classes participated in the study. The two teachers were female and Caucasian. One had 5 years of teaching experience, and the other had 10 years. Each had been recommended by her supervisor and principal as exemplary teachers and had received outstanding-teaching awards from the school district. Both teachers had been trained in their professional-preparation programs to use the Logsdon approach and had continued in-service training with the model through district-sponsored workshops. Each had a master's degree. Both were fieldindependent with scores of 15 and 17 out of 18 on the Embedded Figures Text (Witkin, Oltman, Raskin, \& Karp, 1971).

Students $(N=208)$ in 4 second-grade classes from each of the two programs signed informed consent to participate in the research. They were equally divided by gender (males $=49 \%$ ). Approximately $65.2 \%$ of the students were Cauca- 
sian, $21 \%$ were African-American, $12.7 \%$ were Asian, and $1 \%$ was Hispanic. The average age of the students was 7 years and 2 months. At the conclusion of the 4-month observation period, all students completed the Children's Embedded Figures Test (CEFT; Witkin et al., 1971). Scores ranged from 1-24 out of 24 with higher scores (1st quartile; scores $>17 ; n=52)$ indicating FI and lower scores (4th quartile; scores $<9 ; n=52$ ) suggesting FD. Of the students in the FD sample, $53.8 \%$ were female, approximately $58 \%$ were Caucasian, $28.8 \%$ were African-American, 9.6\% were Asian (primarily Hmong), and 3.9\% were Hispanic. In the FI sample, $55 \%$ were male, approximately $64.5 \%$ were Caucasian, $28.9 \%$ were Asian, and $5.8 \%$ were African-American.

\section{Embedded Figures Test}

The Embedded Figures Tests (EFT; individual, group, children's, and preschool) are used to measure the cognitive restructuring dimension of FDI (Witkin et al., 1977). The Group EFT (teachers) and the CEFT were selected in this study over the traditional Rod-and-Frame Test (RFT) because recent evidence (Linn \& Kyllonen, 1981; Witkin \& Goodenough, 1981) suggested that the RFT measures the FDI perception-of-the-upright dimension rather than cognitive restructuring. Linn and Swiney (1981) demonstrated that, although the FDI dimensions of cognitive restructuring and perception-of-the-upright are related, the former is more closely linked to logical reasoning and general intellectual functioning. Thus, it is more likely to be related to comprehension and the working memory necessary for successful performance in a cognitively focused curriculum.

An early study by Messick and Fritzky (1963) provided a detailed analysis of the construct of field dependence. MacLeod, Jackson, and Palmer (1986) offered evidence to support a relationship between field dependence and spatial ability. Witkin et al. (1971) described the Group EFT as a valid and reliable alternative to the individually administered measures of FDI. They reported correlations of .82 and .63 between scores for male and female undergraduates, respectively. Flexer and Roberge (1983) reported test-retest reliability coefficients (1-year interval) of .78 and .79 for sixth and seventh graders, respectively. Dreyer, Dreyer, and Nebelkopf (1971) obtained correlations between the CEFT and RFT of .61 and .66 for 5-year-old boys and girls, respectively. Coates (1972) adapted the EFT for preschool children. She reported stability coefficients ranging from .39 to .75. The RFT has been adapted less successfully for use with preschool children and is not recommended with this age group.

\section{Data Collection}

Data in the form of observations and formal interviews of teachers and students were collected by the two investigators over a 4-month period (Goetz \& LeCompte, 1984; Howe \& Eisenhart, 1990). At the completion of the observation, EFTs were administered, and interviews were conducted with teachers and students. Each investigator observed four classes once each week at her assigned elementary school. Data were recorded in two journals. The field-note journal consisted of records of events that occurred during the observation period. The interpretive journal consisted of concerns or interpretive comments made by the 
investigators at a weekly meeting to evaluate the previous week's progress and focus the observations for the forthcoming week.

Following the EFT, formal interviews were conducted with teachers and students. The 1-hour interview with each teacher was structured to include three major topics: the teacher's plan for the organization of the class, her efforts to structure material for student learning, and her perceptions of differences in student learning. Investigators used probes to follow up formal questioning. An effort was made to encourage the teachers to elaborate their answers with examples from their classes. Children were interviewed at the conclusion of the observation period. Twenty-six children were selected in a random sample stratified by gender, race, and school. Interviews were limited to 15 minutes and focused on the children's attitudes toward physical education and the relevance of the content to them. Both teacher and student interviews were recorded and transcribed for analysis.

Because EFT data were collected after the observation period, the investigators were not aware of the cognitive styles of the students during the datacollection period. Observations initially focused on classroom events and behaviors of all students. However, as the observation period progressed, the perspective was refined gradually to target students who consistently met the teachers' expectations for appropriate learning behaviors and those who experienced difficulty working within the Logsdon curriculum or who were disruptive.

In this study both researchers were physical educators who had taught in elementary school settings. Because both were officially associated with the university, they were considered outsiders whose role within the school was limited in scope. One of the researchers was Caucasian and the other African, which increased their access to some forms of information and limited others. Efforts were made at weekly meetings to sensitize each investigator to issues of race and culture from the other's cultural perspective, thus acknowledging these differences whenever appropriate.

Teachers served as the key informants for this study. Each was selected because of her expertise in the Logsdon curriculum. In thus study, access to the school environment was limited to a single investigator in order to preserve the quality of the research setting. Investigators met weekly for 3 months prior to and during the data-collection period to coordinate methods in an effort to collect comparable data. Observation and interview protocols were used to increase the consistency of the data across the research sites. Participant researchers, or individuals within the research setting, assisted by examining the data interpretations (LeCompte \& Goetz, 1982). Both teachers assisted the investigators in this way by reviewing data at the conclusion of the study and commenting on its accuracy. Additionally, collaboration between the two researchers served as a form of peer review. Rigorous examinations of the descriptions, interpretations, and conclusions were used to locate discrepancies and facilitate the search for grounded theory.

\section{Data Analysis}

Data from the field-note and interpretive journals and interview transcripts were compared and triangulated using constant comparison (Glaser \& Strauss, 
1967). In this procedure, data were scanned for commonalities or categories. As categories emerged, associated properties were noted and used as rules or definitions for category membership. All statements were then rescanned to ensure compliance with the final category specifications. An effort was made to refine category definitions to the extent that each was mutually exclusive. Each investigator was responsible for the analysis of data from her assigned school. Only those categories that were supported separately in each school and later across the two school situations were included in this report. Additional efforts were made to verify the categories in the literature and to discuss the findings as they related to other research.

At the conclusion of the constant comparison, the observational and interview data were matched with the students' EFT scores. Approximately $92 \%$ of the students who appeared to be learning effectively within the Logsdon approach scored within the 1st quartile of the EFT indicating FI. Students categorized as having learning problems in the observation and interview data represented $89 \%$ of the students who scored in the 4th quartile (categorized as FD).

\section{Results}

Results from this research suggested that the curriculum structure created an environment that was abstract, requiring analysis of movement components and concepts. The content was structured around abstract concepts from the Laban framework, such as spatial awareness, that required students to integrate knowledge with performance. FI children demonstrated appropriate behaviors during the majority of the observed class. They were able to remember and follow directions, work autonomously, respond correctly to teacher questioning, and remain on task throughout the lesson. Conversely, FD children experienced difficulty listening to directions and working autonomously. In this study, teachers used questioning techniques to direct children's attention to important components of content. A range of criteria for successful performances was stated explicitly and used by both teachers and students to evaluate the quality of performance.

In lessons observed in this study, new content was introduced in a direct manner with an emphasis on understanding abstract movement concepts as well as the quality of the physical performance. In these instances, children were asked to visualize or imagine the product of a verbal set of directions. Eleanor Williams, the physical educator at Oak Park Cemetary, explained the practice session emphasizing movement sequencing (all names are pseudonyms):

Eleanor: Girls and boys as you look around the gym you will see bicycle tires, ropes, and benches placed around the room. In our last lesson we practiced jumping in the tires, hopping over the ropes, and galloping across the benches. Today, we are going to use these same movements in sequence. In a sequence, movements follow each other in order. Once you have decided on the order of jumping, leaping, and galloping, you need to remember it so that you can repeat 


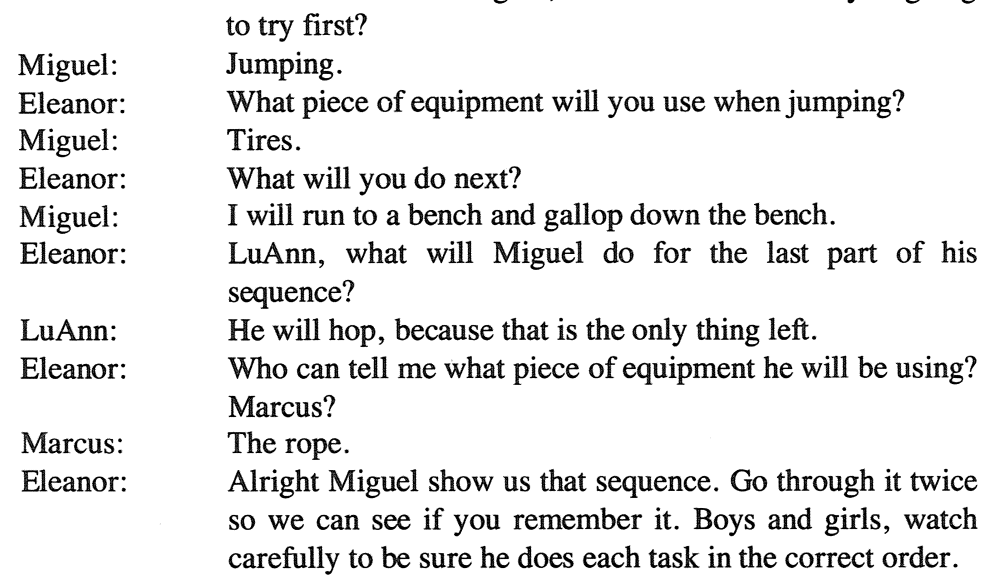
to try first?

Miguel: Jumping.

Eleanor: What piece of equipment will you use when jumping?

Miguel: $\quad$ Tires.

Eleanor: What will you do next?

Miguel: I will run to a bench and gallop down the bench.

Eleanor: LuAnn, what will Miguel do for the last part of his sequence?

LuAnn: $\quad$ He will hop, because that is the only thing left.

it over and over. Miguel, which movement are you going

From the first days of observation, it was clear that some children (later categorized as FI) were more adept at accomplishing these tasks than others. Some listened with their eyes on the teacher, nodding and responding throughout the 10-minute initial presentation. When asked to describe the sequence in which tasks were to be completed, they responded quickly, usually with the correct answer. These students were frequently called on to answer questions and praised for the accuracy of their responses.

\section{Characteristics of Field-Dependent Behavior}

However, many of the field-dependent children within the analytical gymnasium-classroom seemed to experience difficulty attending to directions and working independently. Specifically, they had difficulty focusing on the lesson discussion without touching or talking to other students. Although they, at times, raised their hands to answer questions, when called on, they either did not respond or made comments that were irrelevant to the discussion. When the teacher asked a question regarding prior directions or the serial order of tasks to be completed, they were unable to respond. Teachers described the children as inattentive during the beginning class discussions:

James is a problem in the third period class. He taps his feet and thumps his hands on the floor while the other children and I are trying to talk about the movement (Eleanor).

Most of the children are attentive during our discussion time. But Susan and Laurie have a hard time paying attention. They always seem to be touching other children or each other. They are plaiting each other's hair or smoothing clothes or just hanging on to each other (Pam).

The practice sections of the class were equally difficult for these students. Correct performance was based on the ability to remember the directions and to work through the tasks in a prescribed sequence. Teacher questions were used as instructional cues to initiate the topic and as follow-up probes to further elaborate student answers (Mahlios, 1981). Questions during this phase of the lesson were 
directed toward the analysis of movement, focusing the children's attention on the critical parts of the task as they related to and informed the child about the overall movement concept. Content that was familiar and concrete appeared to be accessible to FD children. However, as the task became more abstract and its purpose more obscure, FD children seemed to experience difficulty relating the abstract concept to the prescribed task. This lack of apparent purpose led to instances of off-task behaviors that were disruptive to the educational environment. For example, Pam Jenkins' lesson at Feldon Elementary, involving a manual ball-dribbling task, was initially received with enthusiasm by her secondgrade students. However, as she refined the task to incorporate dribbling with different parts of the hand and arm, several students, including Ben, had difficulty concentrating on the task:

Initially Ben was proficient at dribbling with his left or right hand and could also dribble with his fingertips, palm, and sides of his hand. However when Pam suggested that students develop a dribbling routine using specific parts of the hand, Ben experienced difficulty. At first he watched Peter, who was using the palm, back, and thumb-side of his hand. When trying to imitate Peter's routine, Ben lost control of his ball and went racing after it. He then stopped to talk with Dennis and kicked Michael's ball that was also rolling out of control. He did not return to his working space, instead paused to look out the window. When the teacher reminded him of the task, he smiled, nodded, and once more returned to his work space to practice the movement sequence (observation from Feldon Elementary).

When a child deviated from the task, as in Ben's case, the teacher moved into close proximity and spoke directly to that individual. Both Pam and Eleanor spent relatively little time on the problem behavior, choosing instead to refocus the student's attention on the content. These children responded quickly to the teacher and attempted to complete the task. As long as the teacher remained close by and supplied the student with positive and supportive feedback, the child worked deliberately to complete the task:

Sometimes I look up and there is Hung Chee. I may have left her at the far side of the room working on a task, and the next thing I know, she is right beside me (Pam).

There are some children who just need to be close to me during our instruction time. They prefer to sit by me and then try to choose a working space that is near where I am standing. This is difficult because I try to move around a lot. These students would learn a lot more if they could just learn to work on their own (Eleanor).

David is a good worker as long as I remember to praise him or use his name when I make a correction or give a demonstration. I would really like for him to work alone, but when I leave him, even for a short period, he becomes distracted and frequently causes problems that take me away from my instruction (Pam).

When attempting to refocus the students on the task, teachers provided verbal reminders of the serial order of the tasks and the criteria for successful 
performance. They continued to question the student regarding the quality of the performance. However, one or more of the other students soon called the teacher away and the pattern of behavior began again, first with innocuous atentionattracting behaviors followed by more disruptive behaviors that distracted other students.

Interviews with the children later identified as FD revealed three concerns, indicating that they too perceived a problem in learning within the analytical format. They reported difficulty in remembering directions, dissatisfaction when working alone, and concerns that the movement tasks were not meaningful. Children expressed concern that they could not remember some part of the lesson:

Sometimes we go to stations and work on jump-rope things. I can't remember what we are supposed to do and which one to do first. It's easier if other children are there too because I can watch them and do what they do (student at Feldon Elementary).

After Ms. Williams told us about the obstacle course, Jeff got to go through it and everybody watched. It was fun to watch him go under and over the benches and jump through the hoops. But later when we were supposed to do it on our own, I forgot which benches to go under and which to jump over (student at Oak Park Elementary).

The teachers in this study frequently provided reminders such as task cards or other cues to help students remember the order of the criteria for a good performance. However, on those occasions when they did not, FD children experienced difficulty with the task. The behaviors discussed earlier by the teachers such as touching other children (hair plaiting, etc.) or foot tapping would suggest a lack of attention. However, there were other children who appeared to be attending and yet could not or did not choose to remember the directions or the criteria for the task.

The second concern mentioned consistently by the FD children was dissatisfaction with having to work alone:

Lots of times when you have to work in your own space, you finish and then there isn't anything to do. You can't go over and talk to someone because you are walking out of your own space (student at Oak Park Elementary).

I like it best when we work with other children. The rolling games are fun. Yesterday we had four kids in our group. We all had to roll across the mat and back at the same time. Sometimes we crashed together, and that was really fun! (student at Feldon Elementary).

When working alone, FD students were more easily distracted than FI children, at times leaving their task to join other children. The value of the experience seemed to increase when they were permitted to work with others. They stayed involved in the activity, interacting positively with other children. There appeared to be a greater sense of involvement and ownership of the task when FD children worked together to accomplish goals than when these children worked alone.

Children also ejxpressed concerns that they did not know why they had to perform certain tasks. In most instances, the teachers had explaiend the rationale 
for the task as it related to learning an abstract movement concept such as force production, but the explanation may have lacked relevance to the FD children and was quickly forgotten:

Today we were hitting the balls with the paddles. We were supposed to keep hitting it against the wall, but it was more fun to hit it hard and see how far it would go (student at Oak Park Elementary).

I don't like to dab. . . . [Dabbing] is when you kick the ball real easy with your foot. . . . [I would rather] kick it ahead and chase it or kick it to someone (student at Feldon Elementary).

I wish we didn't have to start vaulting at the lowest bench. I wish we could climb up on the box and just jump off (student at Oak Park Elementary).

In this study, instruction frequently included a brief explanation of the concept followed by examples and demonstrations to make the content relevant. Teachers asked questions to determine the extent to which students understood the concepts. Observations of the classes to which these children were referring indicated that the teachers spent from 5 to 10 minutes explaining the concept and the task to be performed. For example, in the class on vaulting, the explanation was followed by specific task instructions:

Now, boys and girls, we have three places for you to vault. Each place has a different height so that some are harder and some are easier. Start with an easy place and try one or two vaults. If you are able to vault over the bench without letting your legs touch the bench and can land on two feet without letting your hand or knee touch the mat, then you can move to the next hardest station (field-note data, Oak Park Elementary).

The majority of the children were able to understand the explanation and work successfully on the task. It was not until later, during the interviews, that the FD children's concerns were expressed.

\section{Discussion}

As the data were analyzed, themes and properties emerged to describe major categories of behavior of FD children within the analytical curriculum. Two factors that appeared to influence the learning behaviors of these children were the structure of the class and the opportunities provided for developing interpersonal relationships.

\section{The Role of Structure}

Witkin (1978) noted that FD students are less able to structure situations on their own and thus are likely to seek information from others as a guide for structuring situations. Research by Ausubel (1960) and Allen (1970) into the role of advance organizers as structuring devices provides insight into the learning of FD children. Advance organizers are used to assist individuals in the organization of meaningful material. By previewing the topic prior to discussion, the teacher assists the students by generating an explicit structure. When the teachers in this research assisted the FD student individually, they first provided an organizing structure and then asked questions based on that structure. 
Satterly and Telfer (1979) found similar results with 14- and 15-year-old students. Students classified as FD achieved greatest gains when lessons were structured using advance organizers with specific references to the properties of the organizing concept and the way the concept was to be used to facilitate retention and learning. Additional research by Annis (1979) on study habits suggested that when the organizing structure was evident in a reading assignment, there was no difference between FD and FI eleventh-grade students' ability to respond to comprehension questions. However, when this structure was not immediately evident, the FI students were superior in their ability to impose an effective organizational system and deduce accurate responses.

FD students may further benefit from curricula that are concretely structured, permitting individuals to relate to the problem and find it meaningful. In the curriculum described in this study, the concepts seemed to form an abstract content structure. Children were asked to imagine or mentally visualize aspects of a movement without actually having access to a concrete example. The presentation of class topics by these FI teachers was often conducted in abstract terms, requiring auditory memory, spatial awareness, and visual imaging in order to respond to questions. Although the FI children experienced little difficulty, the FD children seemed to be unable to focus on the abstract concepts. When these children were told to work on a task individually or to compare their performance with the abstract criteria, they seemed unable to impose an internal structure on the task. Consequently, the FD children redirected their attention to other activities that they found meaningful but that were unrelated to the content of the lesson.

The teachers selected for this study were chosen based on their expertise using the Logsdon approach. The analytical curriculum appeared to be compatible with their own FI cognitive styles (Holliday, 1985; Mahlios, 1981). They reported feeling comfortable with the concept-based format and stated that they experienced no difficulty conveying the complex, abstract content to young children. It is logical to think that teachers who are especially adept at teaching analytical curricula are more likely to be FI and thus may select presentation formats and teaching styles that inadvertently increase the conflict between the analytical curriculum and FD children. Additional research is needed to determine the extent to which FI teachers can adapt their presentation structures to include FD children and the extent to which FD teachers are able to mitigate the effects of analytical curricula for FD students (Davis \& Cochran, 1989).

\section{The Influence of Social Relationships on Learning}

Because FD children are less able to structure knowledge on their own, they are likely to depend on information from others as a guide to organizing tasks which lack an obvious structure. Because they do not have the internal referents for structuring ambiguous situations that FI individuals possess, they may experience difficulty working autonomously under these circumstances. Witkin (1978) argued that this dependence on others for structuring encourages FD individuals to develop their capacities for social relationships. In order to receive structural cues from other people, FD individuals selectively attend to social cues in their surroundings. One avenue to receive social cues is by careful attention to the facial expressions of others. Witkin reported that this behavior is 
especially pronounced among FD individuals when they "encounter difficulty with the task confronting them and when the person with whom they are interacting is a likely source of cues in dealing with the problem at hand"' (p. 50). In situations where the task is not perceived to be difficult, the behaviors are not in evidence.

Selective attention is also evident in verbal communication. In experimental studies examining this phenomenon (Witkin \& Goodenough, 1977), FD subjects recognized and recalled significantly more words with social connotations than did FI subjects. No difference was found in neutral words. This information-seeking behavior is also manifest in associations with others because it facilitates access to information (Witkin, 1978). Similar results were found in research that monitored physical space preferences and verbal behavior associated with the distance of the FD person from the information giver. FD individuals preferred to be physically near to those with whom they were conversing (Witkin \& Goodenough, 1977). According to Witkin (1978), when placed at greater distances from the information provider, FD individuals demonstrated gestures such as "mouth touching, lip and tongue activity, and palms-up gestures" (p. 53) that Witkin interpreted as reflecting the anxiety of FD individuals working in the nonpreferred context.

In this study, interpersonal interactions were evident when observing FD children. Triangulation of data from teacher and student interviews and investigator observations confirmed the importance to FD children of working within close proximity to the teacher and other students and the dissatisfaction experienced when asked to work alone. Because the criteria for a successful performance and the increase in self-esteem associated with success are derived from other people (Goodenough, 1976), these children seemed to depend on social relationships for positive reinforcement. Without the capacity to compare their own performance with objective criteria, FD children may not just be working alone, they may be working in isolation. When FD children realized that working with others provided both access to the external structure of the lesson (Witkin, 1978) and an increased level of social comfort, their dissatisfaction with working alone may have intensified.

The centrality of social relationships to the learning process may assume even greater importance when associated with the FD child's ethnic heritage. This was evident when observing a small group of Hmong children $(n=6)$ in 1 second-grade class. The Hmongs are the largest ethnic minority in Laos. Following the United States' involvement in Southeast Asia, many Hmongs immigrated to the United States with political asylum. According to Geddes (1976) the major unit of Hmong social organization is the family, which is headed by the eldest male and includes all married children and grandchildren. The family works as an economic unit with all property belonging to the household. The eldest male has unlimited authority to make family decisions, settle disputes, and impose punishments. Children learn by observation of parents and elders. Child-rearing emphasizes obedience and adherence to the authority of the family, resulting in a high degree of social conformity.

In this study, Hmong children did not participate initially in the lessons. The individually oriented tasks (for example, where each child worked alone with a piece of equipment such as a ball) appeared alien to the working relationships 
promoted within the culture. The Hmong girls either sat quietly or moved to associate with other Hmong girls. Although the Hmong boys participated in the task, they were frequently observed to wander over to other students (most often other Hmong boys) to demonstrate a new skill, or talk, or to work in closer proximity to a friend. Eleanor and Pam occasionally tried to involve the Hmong girls but were successful only for short periods. In these instances, the Hmong girls would attempt to perform the task and continue as long as the teacher was attending to their activity. Numerous examples of eye contact, physical proximity, and responsiveness to touching were recorded in the data. On occasions when the task called for partner or small-group work, the Hmong girls were more involved, although their behavior was frequently not associated with the analytical task. Nevertheless, the teachers were pleased that they were involved and did not intervene to redirect their efforts to the prescribed task. These findings support those of Hvitfeldt (1986) with Hmong adults. She found collaborative teaching styles to be a critical factor when teaching adult Hmong students.

In summary, FD children were more likely to be involved in the learning process when the task was concrete and explained with a demonstration or an example that was meaningful. The opportunity for social interaction not only seemed to increase the comfort and enjoyment level of FD children, but also encouraged the presence of content-related behaviors associated with student learning. As the number of minority and low-income students continues to increase in schools, it is imperative that teachers and curriculum coordinators consider the differences in cognitive styles that may influence the success and failure of these children. By anticipating that FD children will have specific learning problems in an analytical curriculum, teachers can plan strategies that both include the FD child in the educational process and assist them to function more analytically.

\section{References}

Allen, D.I. (1970). Some effects of advance organizers and level of question on the learning and retention of written social studies material. Journal of Educational Psychology, 61, 333-339.

Annis, L.F. (1979). Effects of cognitive style and learning passage organization on study technique effectiveness. Journal of Educational Psychology, 71, 620-626.

Ausubel, D.P. (1960). The use of advance organizers in the learning and retention of meaningful verbal material. Journal of Educational Psychology, 51, 267-272.

Banks, J.A. (1987, April). Ethnicity, class and cognitive styles: Research and teaching implications. Paper presented at the annual meeting of the American Educational Research Association, Washington, D.C.

Bertini, M., Pizzamiglio, L., \& Wapner, S. (Eds.). (1986). Field dependence in psychological theory: Research and application. Hillsdale, NJ: Lawrence Erlbaum.

Bookover, W.B., Schweitzer, J.H., Sneider, J.M., Beady, C.H., Flood, P.K., \& Wisenbaker, J.M. (1978). Elementary school climate and school achievement. American Educational Research Journal, 15, 301-318.

Coates, S. (1972). Preschool embedded figures test. Palo Alto, CA: Consulting Psychologists Press. 
Cohen, R. (1968). The relation between socio-conceptual styles and orientation to school requirements. Sociology of Education, 41, 201-220.

Cohen, R. (1969). Conceptual styles, culture conflict, and nonverbal tests of intelligence. American Antoropologist, 71, 828-856.

Davis, K.J., \& Cochran, K.F. (1989). An information-processing view of field dependence-independence. Early Child Development and Care, 43, 129-145.

Diessner, R., \& Walker, J.L. (1986). A cognitive pattern of the Yakima Indian students. Journal of American Indian Education, 25, 39-43.

Dreyer, A.S., Dreyer, C.A., \& Nebelkopf, E.B. (1971). Portable rod-and-frame test as a measure of cognitive style in kindergarten children. Perceptual and Motor Skills, 33, 775-781.

Ennis, C.D. (1990). Analyzing curriculum as participant perspectives. Journal of Teaching in Physical Education, 9, 79-94.

Ennis, C.D. (in press). Discrete thinking skills in two teachers' physical education classes. Elementary School Journal.

Flexer, B.K., \& Roberge, J.J. (1983). A longitudinal investigation of field dependenceindependence and the development of formal operational thought. British Journal of Educational Psychology, 53, 195-204.

Geddes, W.R. (1976). Migrants of the mountains. London: Oxford University Press.

Glaser, B.G., \& Strauss, A.L. (1967). The discovery of grounded theory: Strategies for qualitative research. Chicago: Aldine.

Goetz, J.P., \& LeCompte, M.D. (1984). Ethnography and qualitative design in educational research. Orlando, FL: Academic Press.

Gonzales, R.R., \& Roll, S. (1985). Relationship between acculturation, cognitive style, and intelligence: A cross-sectional study. Journal of Cross-Cultural Psychology, 16, 190-205.

Goodenough, D.R. (1976). The role of individual differences in field dependence as a factor in learning and memory. Psychological Bulletin, 83, 675-694.

Graham, G., Holt/Hale, S.A., \& Parker, M. (1987). Children moving. Palo Alto, CA: Mayfield.

Hale-Benson, J. (1986). Black children: Their roots, culture and learning styles. Baltimore, MD: Johns Hopkins University Press.

Holliday, B.G. (1985). Differential styles of children's self-perceptions and teachers' perceptions on Black children's academic achievement. Journal of Negro Education, 54, 71-81.

Howe, K., \& Eisenhart, M. (1990). Standards for qualitative (and quantitative) research: A prolegomenon. Educational Researcher, 19(4), 2-9.

Hvitfeldt, C. (1986). Traditional culture, perceptual style, and learning: The classroom behavior of Hmong adults. Adult Education Quarterly, 36, 65-77.

Jewett, A.E., \& Bain, L.L. (1985). The curriculum process in physical education. Dubuque, IA: Wm. C. Brown.

Kagan, S., \& Zahn, G.L. (1975). Field dependence and the school achievement gap between Anglo-American and Mexican-American children. Journal of Educational Psychology, 67, 643-650.

Kogan, N. (1987). Some behavioral implications of cognitive styles in childhood. Early Child Development and Care, 29, 95-117. 
Kogan, N., \& Saarni, C. (1989). Cognitive styles in children: Some evolving trends. Early Child Development and Care, 43, 101-128.

LeCompte, M.D., \& Goetz, J.P. (1982). Problems of reliability and validity in ethnographic research. Review of Educational Research, 52, 31-60.

Linn, M., \& Kyllonen, P. (1981). The field-dependence-independence construct: Some, one, or none. Journal of Educational Psychology, 73, 261-273.

Linn, M., \& Swiney, J.F. (1981). Individual differences in formal thought: Role of expectations and aptitudes. Journal of Educational Psychology, 73, 273-283.

Logsdon, B.J., Barrett, K.R., Ammons, M., Broer, M.R., Halverson, L.E., McGee, R., \& Roberton, M.A. (1984). Physical education for children: A focus on the teaching process. Philadelphia: Lea \& Febiger.

MacLeod, C.M., Jackson, R.A., \& Palmer, J. (1986). On the relation between spatial ability and field dependence. Intelligence, 10, 141-151.

Mahlios, M.C. (1981). Instructional design and cognitive styles of teachers in elementary schools. Perceptual and Motor Skills, 52, 335-338.

Marx, R.W., Howard, D.C., \& Winnie, P.H. (1987). Students' perception of instruction, cognitive styles, and achievement. Perceptual and Motor Skills, 65, 123-134.

Messick, S., \& Fritzky, F.F. (1963). Dimensions of analytic attitude in cognition and personality. Journal of Personality, 31, 346-370.

More, A.J. (1987). Native Indian learning styles: A review for researchers and teachers. Journal of American Indian Education, 27, 17-29.

Nichols, B. (1990). Moving and learning: The elementary school physical education experience. St. Louis: Times Mirror/Mosby.

Oltman, P.K. (1986). Psychological differentiation theory in social and cross-cultural psychology. In M. Bertini, L. Pizzamiglio, \& S. Wapner (Eds.), Field dependence in psychological theory research and application (pp. 84-94). Hillsdale, NJ: Erlbaum.

Resnick, L.B., \& Klopfer, L.E. (1989). Toward the thinking curriculum: Current cognitive research [Yearbook]. Washington, DC: Association for Supervision and Curriculum Development.

Saracho, O.N. (1989). Cognitive style and classroom factors. Early Child Development and Care, 47, 149-157.

Satterly, D.J., \& Telfer, I.G. (1979). Cognitive style and advance organizers in learning and retention. British Journal of Psychology, 49, 169-178.

Wehlage, G.G., Rutter, R.A., Smith, G.A., Lesko, N., \& Fernandez, R.R. (1989). Reducing the risk: Schools as communities of support. New York: Falmer Press.

Winnie, P.H., \& Marx, R.W. (1982). Students' and teachers' views of thinking processes for classroom learning. Elementary School Journal, 82, 493-518.

Witkin, H.A. (1978). Cognitive styles in personal and cultural adaptation. Worcester, MA: Clark University Press.

Witkin, H.A., Dyk, R.B., Faterson, H.F., Goodenough, D.R., \& Karp, S.A. (1962). Psychological differentiation: Studies of development. Potomac, MD: Erlbaum.

Witkin, H.A., \& Goodenough, D.R. (1977). Field-dependence and interpersonal behavior. Psychological Bulletin, 84, 661-689.

Witkin, H.A., \& Goodenough, D.R. (1981). Cognitive styles: Essence and origins. Psychological Issues, Monograph 51, 60-108.

Witkin, H.A., Moore, C.A., Goodenough, D.R., \& Cox, P.W. (1977). Field dependent and field independent cognitive styles and their educational implications. Review of Educational Research, 47, 1-64. 
Witkin, H.A., Oltman, P.K., Cox, P.W., Ehrlichman, E., Hamm, R.M., \& Ringler, R.W. (1973). Field dependence-independence and psychological differentiation: $A$ bibliography through 1972 with index. Princeton, NJ: Educational Testing Service. Witkin, H.A., Oltman, P.K., Raskin, E., \& Karp, S.E. (1971). Manual for embedded figures test, children's embedded figures test, and group embedded figures test. Palo Alto, CA: Consulting Psychologists Press.

\section{Acknowledgment}

The research was funded partially by a grant from the Curriculum and Instruction Research and Development Center. The research was conducted while Catherine Ennis was a faculty member and Jepkorir Chepyator-Thomson was a doctoral student at the University of Wisconsin-Madison. Special thanks are extended to the teachers and students who participated in this study.

STATEMENT OF OWNERSHIP, MANAGEMENT, AND CIRCULATION OF THE JOURNAL OF TEACHING IN PHYSICAL EDUCATION (ISSN 0273-5024), as required by 39 U.S. Code 3685 :

The Journal of Teaching in Physical Education (ISSN 0273-5024) is published 4 times a year (quarterly). Subscription fees are $\$ 32$ per year for individuals and $\$ 64$ for institutions.

The owner of the Journal of Teaching in Physical Education is Human Kinetics Publishers, Inc., whose office is at 1607 North Market St., Champaign, IL 61820-2200. The editors are T.J. Martinek, School of HPERD, Univ. of North Carolina, Greensboro, NC 27412; and J. Rink, Blatt P.E. Center, Univ. of South Carolina, Columbia, SC 29208. The publisher is Rainer Martens, P.O. Box 5076, Champaign, IL 61825-5076. There are no bondholders, mortgagees, or other security holders.

Average number of copies printed per issue (net press run) during the preceding 12 months -1160 ; number of copies nearest to filing date-1272. Average number of copies of each issue during preceding 12 months distributed after mass mailing to subscribers-176; number of copies nearest to filing date -75 . Average number of copies of each issue during preceding 12 months distributed in mass mailing to subscribers-741; number of copies nearest to filing date-974. Average number of copies of each issue during preceding 12 months distributed free-34; number of copies nearest to filing date-30. 